\title{
Lexical Cohesion, Word Choice and Synonymy in Academic Writing
}

\author{
Dr. Leonard Danglli
}

University of Tirana, Faculty of Foreign Languages, Department of English Language Email: leonarduniversity@gmail.com

Dr. Griselda Abazaj

University "Aleksander Moisiu”, Durres., Faculty of Education, Department of Foreign Languages

Email: griselda_abazaj@yahoo.com

\section{Doi:10.5901/mjss.2014.v5n14p628}

\section{Abstract}

This paper discusses the importance of lexical cohesion and word choice in the process of writing. Special attention is paid to lexical synonymy, as a useful and productive tool for increasing cohesion in a piece of writing. A review of studies and approaches to cohesion is followed by a thorough analysis of the role of lexical synonymy in the writing process. Contrary to some beliefs about the risk of synonymy in writing, the paper endeavors to show that correct use of synonyms can add color and accuracy to the text. However, the language user needs to be fully aware of the fact that selecting the right synonym in a given context requires knowledge of all semantic dimensions of the word, which thesauruses alone cannot sometimes give. The paper aims to show that synonyms should be employed by writers as they can perform a number of important functions such as showing the right scale of intensity and level of formality. Moreover, they help writers with accuracy of expression.

Keywords: lexical cohesion, word choice, synonymy, writing, semantics

\section{Introduction}

Just as isolated words are not sufficient for an effective communication, so cannot a group of words meet the intended goal unless properly organized or employed. The functions performed by language relate both to content and form, as a piece of information may convey stylistic or emotional associations in addition to the descriptive meaning. A number of scholars (Halliday, Hasan, 1985) have discussed the ways vocabulary can be used flexibly and appropriately to avoid linguistic rigidity.

Lexical cohesion is considered as one of the most effective ways to meet the above-mentioned expectations. Despite the diverse and numerous studies on lexical cohesion, they all refer to one common consideration, the identification of various linguistic devices to achieve text organization. Therefore, as "when speaking about a topic, we need to refer to the same things again and again and if using the same word each time would be inelegant", (Schmitt, 2000:106) we should then make use of a variety of tools to avoid it.

The model of lexical cohesion designed by Halliday and Hasan (1985) consists of a number of lexical cohesive devices classified into two main categories: reiteration and collocation. Their category of reiteration includes:

- Repetition of the same word (mushroom - mushroom)

- Synonym use (sword - brand)

- Superordinate (Jaguar - car)

- General word (We all kept quiet. That seemed the best move.)

According to Halliday and Hasan (1985), collocation is the cohesion achieved through lexical units reoccurring regularly. Thus, the connection is obtained when the lexical units have the tendency to occur in similar lexical contexts or when they are lexically and semantically related. For example boy and girl are cohesive because they have opposite meanings; laugh and joke, boat and row are also cohesive in spite of not being systematically related but they are typically related to each other.

On the other hand, McCarthy (1988) has designed a model with four lexical relations:

1. equivalence

2. entailment 1: specific - general

3. entailment 2: general - specific 


\section{4. opposition}

If we switch our attention to the tools for achieving cohesion in specific pieces of academic writing such as the paragraph or the essay, we need to consider a number of linguistic devices.

One way to achieve this is "to repeat key nouns frequently in your paragraph" (Oshima, Hague, 1999:41). Here is the example provided to illustrate the way key nouns can be employed throughout the paragraph:

Gold, a precious metal, is prized for two important characteristics. First of all, gold has a lustrous beauty that is resistant to corrosion. Therefore, it is suitable for jewelry, coins and ornamental purposes. Gold never needs to be polished and will remain beautiful forever. For example, a Macedonian coin remains as untarnished today as the day it was minted twenty-three centuries ago. Another important characteristic of gold is its usefulness to industry and science. For many years, it has been used in hundreds of industrial applications. The most recent use of gold is in astronauts' suits. Astronauts wear gold-plated shields for protection outside spaceships. In conclusion, gold is treasured not only for its beauty but also for its utility.

The risk of overusing the key noun is avoided by the use of the relevant pronouns referring to the key noun, called "pronoun references" by Zemach (2005). For example, the pronoun it would be an appropriate substitute for the key noun gold in the paragraph above.

A common way to make a piece of academic writing more cohesive is the use of another linguistic device, namely the "transitions" (Zemach. Rumiseck, 2005:83), otherwise called "transition signals" (Oshima, Hague, 1999:43), or simply linking words by many.

In addition to the above-mentioned cohesive devices, it must be pointed out that word choice is of primary importance when it comes to producing both a coherent and cohesive piece of writing. Commonly referred to as diction, it means "finding and using the word that fits your meaning and tone exactly" (Macmillan English, 1986:83). Moreover, such words "should be appropriate for the writer's purpose, audience, point of view, and tone" (Nadell, 1997:121). Scholars of academic writing generally consider the following aspects of word choice:

- denotation vs. connotation (associated emotions or ideas),

- concrete vs. abstract words,

- general vs. specialized words,

- levels of formality (formal, informal, slang, etc.),

- words that suit the intended tone, etc.

Nevertheless, insufficient attention has been paid to another useful linguistic device, lexical synonymy, which could increase the lexical cohesion of a piece of writing. Discouragement may have stemmed from such statements as "confusion results from synonym use", "Do not indulge in overuse of a synonym dictionary", "Synonyms always confuse or irritate readers" (Norris, 2014). While these statements may be partly true with reference to the use of synonymy in certain kinds of writing (technical writing for example) or misuse of synonymy by writers whose knowledge of synonyms is inadequate, they do not undermine the numerous expressive possibilities provided by the employment of the right synonym in the right context.

It is also true that the linguistic phenomenon of synonymy sometimes tends to be oversimplified by language users, i.e. they consider two or more synonyms as words with the same meaning, interchangeable in any given context, thus neglecting the really fine but essential shades of meaning, which, if not taken into consideration, may spoil the overall stylistic picture of a piece of writing. Selecting one synonym instead of another means taking into account at least one of the following dimensions of synonym differentiation:

1. Denotation (what Lyons (1995) calls descriptive synonymy)

2. Style

3. Collocation

The simplistic use of such a complex linguistic device results in the use of inappropriate synonyms in a piece of writing, thus producing a negative impact on either the tone, accuracy or even intended message of the piece of writing.

Another factor bringing about the misuse of synonymy is misunderstanding the role of thesauruses. Those lists of synonyms (in most cases near-synonyms, or simply semantically related words) do not always imply interchangeability. They remind us of words of a certain semantic resemblance, but it is then up to the (professional) user to distinguish one from the other by using other books of reference or test them in a variety of contexts. If this differentiation process is not completed, we may end up using what I call "thesaurus synonymy", i.e. using lists of synonyms from thesauruses without taking into account the differences which prevent them from being interchangeable. This is reinforced by Nadell $(1997: 123)$ who claims that "even two words listed as synonyms in a dictionary or thesaurus can differ in meaning in important ways".

A lot of textbooks underline the risks of misusing synonymy. Bailey (2003) states that "when writing it is necessary 
to find synonyms in order to provide variety and interest for the reader". However, he gives the following warning to his book users:

"synonyms are not always exactly the same in meaning, but it is important not to change the register. Firm is a good synonym for company but boss is too informal to use for manager. Both pupil and student could be used to identify a 15-year-old schoolgirl, but when she goes to university only student is normally used. Scholar might be a possible synonym, but it is very formal. Similarly, at university a lecturer could also be called a teacher, but in school the only possible synonym for teacher is the old-fashioned master or mistress".

Nevertheless, many claim that "knowledge of synonyms can help you improve your writing vocabulary. Instead of repeating the same word over and over, you can you use a synonym" (Macmillan English, 1986:554). The following examples are provided as possible substitutes:

- respond - answer

- impede - obstruct

- reluctant - hesitant

- chains - shackles

- evident - obvious

- signify - mean

- admonition - reprimand

- remnant - remainder

- pertinent - relevant

These examples show that synonymy extends our lexical choice and provides us with a myriad of opportunities to "avoid the repetition of words and add color and variety to the language" (Colona, 2006:49).

It is obvious that lexical choice is greater when the language user is given the possibility to choose between the members of the following pairs or sets of synonyms: finish - end - terminate; alter - change; achieve - reach; concentrate focus; confine - limit; improve - ameliorate - get better; found - establish - set up; trend - tendency; component - part; begin - start - initiate - commence.

The importance of using synonyms as tools for avoiding text "monotony" has been highlighted by Tuttle (2009), who gives the example of the paragraph below to show how the repetition of the same word within one paragraph should be avoided.

Ralph, Tom's dog, is very fast. He is so fast that I cannot keep up with him. Ralph is so fast that he can catch a thrown ball before it hits the ground. He is a fast runner; he almost catches cars.

"Synonyms can also serve the purpose of describing research results to support thesis statements. For example, a number of related words can be used to replace the verb said such as commented, stated, added, reported, emphasized, stressed" (Colonna, 2006:108).

In addition to adding variety, synonyms can also perform a number of semantic roles in a piece of writing.

Two or more synonyms (or sometimes semantically related words) can be employed to emphasize the degree or intensity of the quality/action being described. A writer can therefore choose between the following pairs of synonyms, with the second member being of a greater intensity or emphasis: dirty - filthy; hot - boiling; cold - freezing; tired exhausted; big - enormous; tasty - delicious; small - tiny; old - ancient; happy - exhilarated, etc. Intensity can sometimes increase progressively throughout the synonymic set, with the first member of the synonymic set standing at the bottom of the intensity scale and the last member of the synonymic set standing at the top of the intensity scale: to like, to admire, to love, to adore, to worship. However, an accurate scale of synonymy in such cases may prove difficult as the associations created by the different members of the synonymic set may sometimes vary from person to person.

In many instances, differences in intensity can be combined with differences in shades of meaning, especially in sets with a great number of synonyms such as happy, pleased, thrilled, glad, contented, ecstatic, exultant, joyful or angry, mad, furious, wrathful, indignant, enraged, exasperated.

Synonyms can be used to convey the right level of formality. When it comes to academic writing, style is of paramount importance. This is the reason why a number of tables with academic writing words have been designed to provide writers with possible and appropriate words to be used in a piece of academic writing. You will find below words extracted from such a table (Bailey, 2003:109-110):

results - findings; area - field; authority - source; benefit - advantage; category - type; component - part; behavior - conduct; output - production; expansion - increase; option - possibility; trend - tendency; drawback - 
disadvantage; assist - help; achieve - reach; concentrate - focus; show - demonstrate; found - establish; predict forecast; retain - keep; strengthen - reinforce; eliminate - remove.

Schmitt (2000) discusses the role of language formality by referring to the distinction of the English vocabulary between Old English and Greco-Latin vocabulary, with the latter giving discourse a more formal or academic tone. Such examples as brotherly - fraternal, kingly - regal, happiness - felicity, empty - vacuous, demonstrate the difference along the formality scale between the members of the synonymic pairs, with the second member of the pair showing a greater level of formality. formal:

Jackson (1988) offers the following list of synonyms, with the first member of the pair of synonyms being more

Table 1. Formal vs. neutral words

\begin{tabular}{|c|c|}
\hline Formal & Neutral \\
\hline pulchritude & beauty \\
\hline decease & die \\
\hline missive & letter \\
\hline caveat & warning \\
\hline eulogy & praise \\
\hline occidental & Western \\
\hline traverse & cross \\
\hline renounce & give up \\
\hline toxophilite & archer \\
\hline disputation & argument \\
\hline purchase & buy \\
\hline
\end{tabular}

Accuracy of meaning can be achieved through the use of the appropriate word. For example, attention must be paid to the discrimination of meaning between such words as walk - stroll - stride - saunter ; see - gaze - stare - glimpse; laugh - giggle - chuckle; Despite their considerable semantic overlap, the members of these sets differ in certain semantic components, which are essential to the accuracy of the expression. The need for accuracy is reinforced by C S Lewis's statement: "Don't use words too big for the subject. Don't say "infinitely" when you mean "very"; otherwise you'll have no word left when you want to talk about something really infinite."

Writers can better express their attitude by choosing the word which best suits their intended effect (generally based on purpose and audience). The expression of positive and negative attitudes can be facilitated by the employment of synonyms (near-synonyms) of either positive or negative connotation. Such examples include politician - statesman, skinny - slim; goof - error, etc.

Word choice also depends on the collocational possibilities of words. The table below clearly shows the collocational differences between the words big, large and great. In spite of their semantic overlap, these three words have their typical collocates.

Table 2. Collocational restrictions of big, large and great (OALD, 2000:109)

\begin{tabular}{|c|c|c|}
\hline big & large & great \\
\hline man & numbers & success \\
\hline house & part & majority \\
\hline car & area & interest \\
\hline boy & room & importance \\
\hline dog & company & difficulty \\
\hline smile & eyes & problem \\
\hline problem & family & pleasure \\
\hline surprise & volume & beauty \\
\hline question & population & artist \\
\hline difference & problem & surprise \\
\hline
\end{tabular}

The arguments presented above show that the writing process is closely linked with lexical cohesion and word choice. The latter is of primary importance when it comes to expressing the intended meaning in any piece of writing. However, in 
academic writing, being the main focus of this study, special attention is paid to the different dimensions of meaning. Lexical synonymy can be used by writers to make a piece of writing both more cohesive and colorful. Synonyms can be employed by writers to add variety to their piece of writing, thus avoiding inappropriate repetition of the same word. Moreover, sets of synonyms give writers the possibility to choose the word which best suits the tone and intended audience. Accuracy can also be improved by using the word which fits the context. Nevertheless, synonymy, while both interesting and useful, if not used properly, may produce the opposite effect, that of distorting meaning or the tone of writing. As a result, whenever we think of replacing a word with a synonym (near-synonym), we should not just "pick" one from the myriad of words in a thesaurus but test its appropriateness in the context you intend to use it. If the search for an appropriate synonym is unsuccessful and the use of a similar word would spoil accuracy, we had better take Crowley's advice: "repetition is not necessarily negative; if used with mastery, it is a figure of speech" (Crowley, 1994:202).

\section{References}

Bailey, S. (2003). Academic Writing, a practical guide for students, RoutledgeFalmer.

Colonna, M. \& Gilbert, J. (2006). Reasons to Write, Oxford University Press.

Crowley, Sh. (1994). Ancient Rhetorics for contemporary studies, Allyn and bacon.

Halliday, M.A.K \& Hasan, H. (1985). Cohesion in English. Longman.

Jackson, H. (1988). Words and Their Meaning. Longman.

Lyons J. 1995. Linguistic Semantics. Cambridge University Press.

Macmillan Publishing House. (1986). Macmillan English (third edition), New York.

McCarthy, M. (1988). Some vocabulary patterns in conversation; In R. Carter \& M. McCarthy (Eds.), Vocabulary and Language Teaching. (pp. 181-200). London \& New York: Longman.

Nadell, J. (1997). The Macmillan Writer, Rhetoric, Reader, Handbook, Allyn \& Bacon.

Norris, C. B. (2014). Academic Writing in English, University of Helsinki.

Oshima, A. \& Hogue, A. (1999). Writing Academic English, 3 rd Ed. White Plains, NY: Longman.

Oxford Advanced Learners Dictionary. (2000). Oxford University Press.

Schmitt, N. (2000). Vocabulary in Language Teaching. New York: Cambridge University Press.

Tuttle, H.G. (2009). Successful student writing through formative assessment. Routledge. 